\title{
Designation differences and academic career progression
}

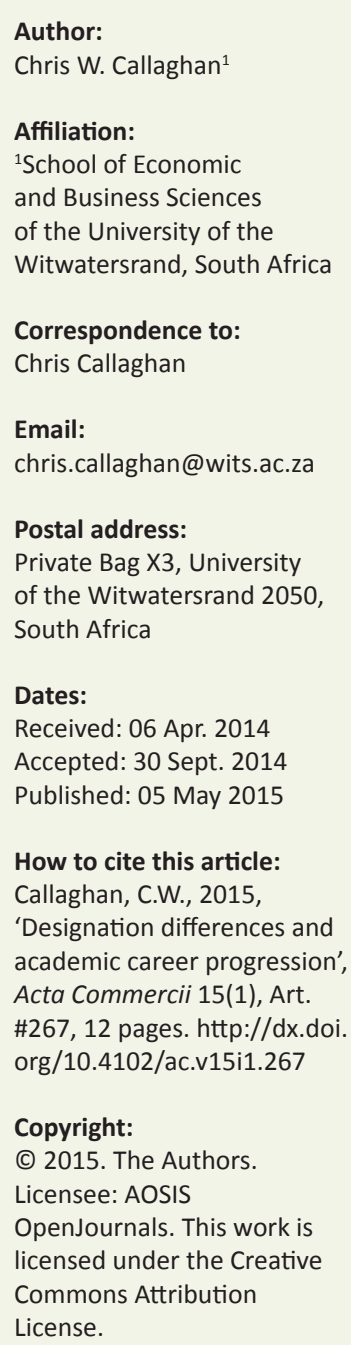

\section{Author:}

Affiliation:

(n)

of the University of the

Witwatersrand, South Africa

Correspondence to:

Email: of the Witwatersrand 2050,

Dates:

Received: 06 Apr. 2014

Accepted: 30 Sept. 2014

How to cite this article:

Callaghan, C.W., 2015,

'Designation differences and ession, \#267, 12 pages. http://dx.do org/10.4102/ac.v15i1.267

\section{2015. The Authors Licensee: AOSIS \\ OpenJournals. This License.}

Read online:
Orientation: According to the human resources literature, academics may need to 'balance' certain issues in order to enable career progression.

Research purpose: This research sought to test the theory that predicted differences between individuals by designation cohort membership ( $\mathrm{Mr} / \mathrm{Ms}$, doctoral and professorial designation) in order to make recommendations for how academic staff could better facilitate their career development.

Motivation for the study: This research attempted to identify certain 'crisis milestones' that reflect potential role conflicts that may constrain academic career progression.

Research design, approach and method: Academic staff of a large South African university (with over 30000 students) provided the sampling frame for an empirical study. Using logistic regression, three career markers that reflect different career cohorts - Mr/Ms designation, doctoral designation and professorial designation - were each regressed on a range of biographical and contextual factors derived from the literature and a comparative analysis was performed.

Main findings: Findings suggest that these cohorts differ significantly according to: satisfaction with teaching; satisfaction with administration; research self-efficacy; and dependent children. 'Crisis milestones', potentially related to role conflicts, might need to be resolved before career progression to doctoral and professorial designations can occur.

Practical/Managerial implications: Knowledge of these 'crisis milestones' can be used to help academics to manage role conflicts and issues. This might remove unnecessary constraints to academic career progression.

Contribution/Value add: This study provides new insights into certain 'crisis milestones', or role conflicts or issues, that may need to be resolved or balanced before the career progression of academics can typically occur.

\section{Introduction}

$[I]$ t is extremely hazardous for a young scholar without funds to expose himself to the conditions of the academic career. He must be able to endure this condition for at least a number of years without knowing whether he will have the opportunity to move into a position which pays well enough for maintenance. Weber 1919:524

Academic employment has, perhaps, changed substantially since Max Weber's (1919) perspective of academic career progression, particularly in terms of gender equality, language usage and career terms.

Although the academic institution has undoubtedly changed over time, it is argued that this process (academic career progression) is still dominated by hazards, in the form of 'crises milestones', which individuals need to successfully traverse, or negotiate, and resolve in order to progress along the academic career path. It is debated that at the heart of Weber's (1919) argued hazards associated with academic career progression is a notion that is no less pervasive in the contemporary context. For Weber (1919:528), the tension between teaching and research poses a dominant constraint to career progression; whether 'the abilities for both [teaching and research] are found together in a man is a matter of absolute chance'. Academic life can therefore be 'a mad hazard', according to Weber (1919:528).

More contemporary meta-analysis findings also support the notion that teaching and research are dominant and potentially conflicting roles in academic careers (Hattie \& Marsh 1996). This is, however, but one dimension of a range of potential influences that might have an impact on an academic's career path and progression. This research seeks to identify the primary 
dimensions of these, nested as they are within the South African context of higher education.

South Africa has 'an educational context beset with poverty, the legacy of apartheid and the impact of HIV/ AIDS, and where the quality of teaching is universally described as poor' (Deacon, Osman \& Buchler 2010:1). This democratised context, however, is also itself nested within a global context of education that is shifting toward more democratic and inclusive ways of working, whilst at the same time higher education institutions are under increasing pressure to compete with 'the best in the world' (Nundulall \& Reddy 2011:1155).

\section{Objectives and contribution to the field}

Academic rank advancement, or career progression, has been well researched. Despite much literature that relates to dimensions of academic career progression, little research has been conducted on specific career differences between individuals at different levels of career progression in the South African context of higher education. These specific differences are considered to reflect crisis milestones, or challenges that need to be resolved in order to progress to doctoral and professorial designations in an academic career. Research into these milestones is taken to be important for the following reasons.

Firstly, Weber's (1919) arguments are reflected in more contemporary work. In the global context, academia has been described as a 'three-ring circus', where research, teaching and service comprise responsibilities that are 'timeconsuming, diverse, and conflicting' (Toews \& Yazedjian 2007:113). Many academic activities are not recognised and career progression can become disproportionately associated with one measure of research output: the publication of journal articles (Mbali 2010). Without a clear understanding of the relative influences on career progression, the requisite balance between investments of time and resources may not be known. This lack of knowledge of how to balance academic roles and investments could constrain the progression of academics in this context.

\section{Faculty members typically:}

find themselves balancing multiple roles within and outside of their organisations, often leading to role ambiguity; dealing with stress and conflict that result from unclear responsibilities and expectations combined with what they believe are vague criteria for evaluating their success; and handling an increased work-load which can lead to a feeling of being overloaded as they move through the academic and administrative ranks. (Brazeau \& Woodward 2012:1)

This is also the case in South Africa; in this context, academics have complained frequently of role overload (Pienaar \& Bester 2008).

The research productivity literature suggests that time investments in research can be the strongest predictor of research output (Toews \& Yazedjian 2007). Although seemingly associated with the most urgent requirements, whilst 'teaching is extremely valuable, it is not a sufficient condition for receiving tenure' (Toews \& Yazedjian 2007:114). Similarly, service work (including committee work), is 'not highly regarded when making tenure decisions' (Toews \& Yazedjian 2007:114). Time constraints therefore exist at the nexus of these different academic work roles. Attaining a balance between teaching, service and research roles (whilst not neglecting any) may be particularly important for career progression, particularly as inequities in recognition and rewards persist with regard to teaching versus research.

Secondly, academic roles might still be changing over time. Academic roles may be trending toward general corporatisation (Rabe \& Rugunanan 2011). The influence of educational technologies is also increasing (Lautenbach 2010). Another requirement is influencing academic work and its associated roles: the need to bring in external income in a context of decreasing state funding (Toews \& Yazedjian 2007). Research that offers a perspective of the factors associated with different career cohort levels can also place these 'local' milestones in relation to literature that relates to changes on the global level. This research therefore investigates boundary conditions to career theory derived in other contexts. Global theory and research findings might not necessarily generalise into the South African context. This study provides knowledge of career milestones that is specific to this context and that can be used to improve the career development of academics.

Thirdly, academic exit, or turnover, is a global problem as well as a problem in this context, as academic skills take a long time to develop and are typically the result of extensive experience (Pienaar \& Bester 2008). Turnover of staff can impose economic costs on an organisation and can disrupt its social and communicative structures (Robyn \& Du Preez 2013). Employee engagement and job satisfaction can mitigate intention to quit (Robyn \& Du Preez 2013). Knowledge of the specific issues associated significantly with different career markers, or designations, can be used to manage these milestone transitions and to increase the engagement and job satisfaction of academics making these transitions.

Knowledge of career milestones may enable their management through contributing to lower turnover rates which, in turn, might contribute to the sustainability of the country's institutions and South African higher education (Pienaar \& Bester 2008). South Africa's education system has been rated the fifth worst in the world (World Economic Forum 2012); research that effectively contributes to its management can benefit societal stakeholders.

Having introduced the study, literature is now reviewed and the theoretical framework of the research is outlined.

\section{Theory and literature review}

The multiplicity of academic work roles and their relative inequity with regard to rewards and career progression seems to be a dominant theme in the academic literature. 
This inequity may have a range of different consequences, but at the individual level, dissatisfaction and academic exit are particularly important.

The exodus of academics from higher educational institutions is a problem in the South African context (Rabe \& Rugunanan 2011:62). Career uncertainty in academia is fundamentally problematic and can lead to academic exit (Rabe \& Rugunanan 2011). Pienaar and Bester (2008) argue that the academic profession, particularly in the South African context, is increasingly stressful, no longer enjoying 'its previous status and prestige'. Junior scholars are being lost to state or private employment because of the global and local trend toward general corporatisation and contract labour; failure of career progression in the form of tenure attainment is an important reason for exit (Rabe \& Rugunanan 2011). Without effective career progression, many academics in this context also exit because of financial reasons; differentials between private sector work and academia are problematic (Rabe \& Rugunanan 2011). Constraints to career progression, however, might be related to the failure to balance different career roles.

The tension between teaching and research as academic roles seems to dominate the academic career literature. Teaching requirements can sometimes seem overwhelming (Toews \& Yazedjian 2007) - academics must therefore find 'practical ways to negotiate this tension' (Toews \& Yazedjian 2007:118). Notwithstanding the benefits of integrating research into teaching (Burke \& Rau 2010), teaching and research remain fundamentally different roles (Hattie \& Marsh 1996) and necessarily compete for resources, including time resources (Fox 1992), which are increasingly constrained in contemporary academic contexts (Toews \& Yazedjian 2007).

If time investments in research are typically the strongest predictor of research output (Toews \& Yazedjian 2007), then time investments in other activities may conflict with research. Research productivity might be especially sensitive to time investments - time spent on teaching has been found to predict significantly lower levels of research productivity (Barbezat 2006). Balancing these roles may be particularly important, so that neither role is neglected.

This tension between teaching and research is reflected in meta-analysis findings (Hattie \& Marsh 1996). Although cognitive ability might contribute to task performance in both roles (as an underlying cognitive construct: the ' $\mathrm{g}$ ' model), the skills and knowledge invested in productivity in teaching do not necessarily contribute to productivity in research (Hattie \& Marsh 1996). According to the 'scarcity model', teaching conflicts with research because both activities compete for time and resource investments (Fox 1992; Hattie \& Marsh 1996).

Typical milestones in an academic career include the attainment of tenure (or permanent appointment) and the attainment of professor status (Su 2014). Tenure may typically be dependent on attainment of a doctorate.
Progression is, however, often associated with uncertainty; it can be a function of the dynamic interplay between a wide range of influences, including an individual's human capital investments as well as social networks (Lam 2007; Su 2014). This research draws from human capital theory (Becker 1964) as a theoretical framework; where crisis milestones are largely considered to be challenges related to investments of learning and knowledge. The implication is that these crisis milestones can be overcome, or managed, through learning. However, knowledge of what these constraints are is necessary in order to manage them.

Following human capital theory (Becker 1964), academic role investments in certain skills and knowledge may pay off in general roles (this is termed 'general' human capital), or may not pay off in general roles but only in specific roles (this is termed 'specific' human capital). The implications of the lack of transferability of human capital investments are considered to be of particular importance for the career development of academics. Investments in learning related to teaching, for example, might be a form of specific human capital if its investments result only in productivity increases in teaching but not in research.

Academic roles, however, also conflict in their use of resources, of which time is one dimension (Fox 1992; Hattie \& Marsh 1996). Academics typically follow two career paths: (1) a path reflected in designations, namely, the $\mathrm{Mr} / \mathrm{Ms}$ designation, the doctoral designation and the professorial designation; and (2) a managerial, or administrative, path that exists within the academic path (Leonard 1987). This research is delimited to the former category. Research productivity, however, is understood primarily as underpinning the attainment of doctoral designation and professorial promotions (Su 2014).

Different careers have different structures (Driver 1994); the traditional career associated with one or a few employers has largely given way to a 'career progression paradox', where individuals need to acquire work and 'develop skills in new areas but find that employers prefer those with continuous prior experience' (O'Mahony \& Bechky 2006:919). This, however, is less typical of 'stable state' career paths (Driver 1994), such as academia, which, even if more stable, still reflects characteristics akin to an internal labour market (O'Mahony \& Bechky 2006) that allocates labour, determines the scope of different jobs and determines remuneration according to procedures, including those that relate to career progression.

However, because of the seemingly singular nature of the underlying driver of career progression, which is research productivity or, more specifically, journal article publications (Mbali 2010), it is argued that crisis milestones can be identified for academics in this context in a way that would be more difficult for other professions.

The academic profession is, to some extent, atypical of other professions; it is a closed positioning system as those that attain a position in it can typically remain there for 
the rest of their careers (Röbken 2009). Unlike instances where individuals move from specialised toward generalist managerial positions over time (Srour et al. 2013), the focus of this research is delimited to investigating the linear path from entry to doctoral designation and then to professorial designation level. However, notwithstanding this delimitation, differences between academic fields also exist - these have the potential to introduce a dimension of variance into the testing process.

Academics in different fields typically achieve tenure at different rates. Academics in engineering, computer and mathematics fields generally acquire tenure sooner than those in the biological or physical sciences (Su 2014). The use of journal article publication as the primary basis for career progression, particularly in the South African context, favours the disciplines of Natural Science and Engineering (NSE) and moulds other disciplines of Social Sciences and Humanities (SSH) to their values and modes of working' (Mbali 2010:745). This research, however, attempts to provide evidence of the tested relationships that to some extent are robust to, or generalise across, disciplinary influences. Relationships common across fields will be expected to dominate in the empirical testing. Those that do not generalise across fields will be expected to have weaker tested associations. Another dimension of variance expected to be reflected in the results are differences between individuals, or individual differences.

Individual motivational drivers of career progression are not constant over the course of a career; these are most commonly linked to past, current and predicted future career experiences (Brown-Wilson \& Parry 2013). Individuals might have different motivation to invest in different academic roles that conflict with each other in terms of time and resources; such as teaching versus research, reflecting the ever-present conflict between these roles (Hattie \& Marsh 1996).

If investments of time are needed to improve research skills, then research productivity might be sensitive to other time investments. This sensitivity would be expected to reflect in lower levels of research productivity for individuals that drive their primary job satisfaction from teaching. Satisfaction with teaching is therefore expected to be associated negatively with research output and, therefore, with career progression by designation. On the basis of this literature, general job satisfaction, satisfaction with teaching, satisfaction with research and satisfaction with administration were all included in the analysis. The investment of time in an activity is not, however, only related to a preference for an activity but also derives from self-efficacy related to the specific activity (Bandura 2006). This, according to Bandura, is a dominant determinant of an individual's investment of time in an activity.

The investment of time and effort in an activity is a direct function of self-efficacy, because self-efficacy beliefs:

influence the course of action people choose to pursue, the challenges and goals they set for themselves and their commitment to them, how much they put forth in given endeavours, the outcomes they expect their endeavours to produce, how long they persevere in the face of obstacles, [and] their resilience to adversity. (Bandura 2006:309)

What is clearly implicit in Bandura's (2006) theory is that perseverance and the continued investment over time in activities in the face of other challenges is sustained by an individual's levels of self-efficacy related to those activities. On the basis of this body of theory, a measure of selfefficacy relating to research productivity was included, on the assumption that research productivity (Mbali 2010) in this form of steady-state career (Driver 1994; Röbken 2009) may fundamentally underpin career progression. Having considered theory that may relate to the dominant influences, or core crisis milestones of academics in this context, other subordinate influences are now also considered, which may have influences on career progression. These include the potential influence of gender, marriage and dependent children, which relate to the need to find work versus family balance (Dilworth 2004; Dilworth \& Kingsbury 2005) in support of career progression.

Less gender-inequality exists in contemporary working contexts, yet gender differences persist; even in professional fields (Walsh 2012). Working mothers typically experience higher negative family-to-work spillover than fathers (Dilworth 2004), as well as role inequality in childcare and house work (O’Brien \& Hapgood 2012). The ability to balance family and work roles is another potential crisis milestone in academic career progression, given the potential sensitivity of research productivity to time constraints (Toews \& Yazedjian 2007).

As indicated previously, although this research applies statistical methods and cannot, therefore, claim causal relationships, the core argument of this study is that the progression across designations for academics in this context is path dependent; that there are certain 'issues', or 'crisis milestones', of various sorts that need to be resolved before an individual moves to the next career stage designation. Framed from the vantage point of human capital theory (Becker 1964), these issues, or crisis milestones, are taken to reflect a complex nexus of intrinsic preferences, beliefs (including self-beliefs) and behaviours, that contribute to investments in research skills and knowledge over time (human capital) and which, in turn, contribute to research productivity and career progression. Following Becker (1964), it is argued that changes in the structure of allocations of investments in learning and knowledge related to these issues can result in improvements in research productivity.

Although differences in academic fields were discussed above, it is necessary to also consider differences between academic precedents that relate to geographic regions of the world. This is yet another 'dimension of variance' that needs to be taken into account. Academics in certain contexts are subject to disciplinary, geographical or national paradigms (Röbken 2009). For example, in the German context the publication culture requires a commitment to normative nonempirical research as opposed to the international culture, 
which is more accepting of empirical work (Röbken 2009). Given that South Africa employs academics from different regions of the world, in order to ensure that these differences (between quantitative and qualitative approaches) did not confound the analysis of other effects, a covariate measure of preference for quantitative versus qualitative methods was included. The inclusion of years as a researcher allowed for control of the influence of experience; tested associations between other variables and the dependent variables were taken to be net of the influence of experience.

On the basis of the literature reviewed above, the following hypotheses were derived:

1. Hypothesis 1: There is a significant association between $\mathrm{Mr} / \mathrm{Ms}$ designation and biographical and contextual factors.

2. Hypothesis 2: There is a significant association between doctoral designation and biographical and contextual factors.

3. Hypothesis 3: There is a significant association between professorial designation and biographical and contextual factors.

Having presented theory and hypotheses that relate to the tested relationships of this research, the methods applied in the study are now discussed.

\section{Research methods and design}

An exploratory cross-sectional associative research design was applied, with all the lecturing staff of a large South African university comprising the sampling frame of the study. The epistemological and ontological assumptions of the research were consistent with the paradigmatic prescriptions of post-positivism (Cresswell 2003).

\section{Data collection and analysis}

The entire institution was sampled using a process of purposive comprehensive sampling. All refusals to participate were respected unconditionally. Respondents that decided to participate voluntarily were able to return completed questionnaires in pre-addressed envelopes through the institution's internal mail system. Of about 1300 total staff, including part-time and full time staff, 225 usable responses were analysed. SPSS 21 (IBM Corp., Armonk, NY 2012) was used for the analysis. A sample size calculation indicated that inferential interpretations at the $5 \%$ level of significance could be made. Representativeness of the sample was broadly confirmed through a check of the relative proportion of responses from staff without doctoral qualifications ( $46 \%$ of the sample), versus those with doctorates yet without professorial designation $(31.7 \%$ of the sample), versus associate professors (13.8\%) and full professors $(8 \%)$.

Multivariate tests were used to test relationships predicted by theory in order to either support or reject the null hypotheses. Logistic regression was used because it was able to include a range of variables in the equations tested. This was taken to offer a test of relationships that might better reflect how effects operate in the real-world context; human capital influences are not expected to operate independently of each other. The scales, or measures, of the variables tested in this study are now discussed.

\section{Scales/measures}

Job satisfaction measures comprised three items in the form of seven-point Likert-type scales (Alpha $=0.859)$, drawing from the precedent offered by the Minnesota Satisfaction Questionnaire scales (Arvey et al. 1989; Muchinsky 1983). The satisfaction with teaching, administration and research items were also adapted from this precedent. Drawing from Bandura's (2006) theory and prescriptions, the following selfefficacy dimensions were included: self-efficacy relating to (1) Thomson Reuters Institute for Scientific Information (ISI)/ Proquest International Bibliography of the Social Sciences (IBSS) indexed journal article publication; (2) Department of Higher Education and Training (DOHET)-accredited journal article publication; (3) conference proceedings publication; (4) conference presentations; (5) postgraduate teaching selfefficacy; (6) statistical analysis self-efficacy; and (7) qualitative analysis self-efficacy. The items were piloted before use in the final instrument. The alpha value for the seven self-efficacy items was 0.783 . A summative measure was also used in the analysis. Gender and marital status were measured as binary variables. A ratio item measured dependent children and a Likert-type item was used to measure an individual's preference for quantitative versus qualitative methods. Years as a researcher were measured as a ratio item. Research output was measured as a cumulative, or additive, function of an individual's endowment of ISI/IBSS indexed journal article publications, DOHET-accredited journal publications, conference presentations, conference proceedings and book chapters published.

\section{Characteristics of the sample}

Tables 1, 2 and 3 report the descriptive statistics for the three cohorts; individuals with the $\mathrm{Mr} / \mathrm{Ms}$ designation (Cohort 1, or C1), with doctoral designation (Cohort 2, or C2), and professorial designations (Cohort 3, or C3), respectively. Mean job satisfaction is lower for $\mathrm{C} 2$, relative to the other two cohort groups. $\mathrm{C} 1$ has relatively higher mean levels of satisfaction with teaching, yet the lowest satisfaction with administration and research.

$\mathrm{C} 1$ also has the lowest levels of research self-efficacy. Female academics dominate the $\mathrm{C} 1$ and $\mathrm{C} 2$ cohorts, but $63.3 \%$ of $\mathrm{C} 3$ are male. Whereas the age means for the cohorts are 37.3 (C1); 40.5 (C2) and 48 (C3), the means for their years of experience as a researcher are $6.02(\mathrm{C} 1) ; 10.39(\mathrm{C} 2)$ and 18.89 (C3). These descriptive statistics suggest that career progression is also a function of time spent as a researcher in this context.

The mean value for preference of quantitative methods is higher for the C2 cohort. On the whole, these differences 
TABLE 1: Descriptive statistics: Mr/Ms designation.

\begin{tabular}{|c|c|c|c|}
\hline Variable & Mean/Proportion & Median & Standard deviation \\
\hline Job Satisfaction & 15.73 & 15 & 3.85 \\
\hline Satisfaction with teaching & 4.81 & 5 & 1.5 \\
\hline Satisfaction with administration & 2.08 & 1.5 & 1.40 \\
\hline Satisfaction with research & 4.60 & 5 & 1.43 \\
\hline Self-efficacy research & 375.88 & 391 & 108.30 \\
\hline Self-efficacy DOHET publication & 62.36 & 60 & 25.23 \\
\hline Self-efficacy conference proceeding publication & 68.78 & 70 & 24.87 \\
\hline Self-efficacy conference presentations & 73.48 & 80 & 22.66 \\
\hline Self-efficacy statistical analysis & 48.1 & 50 & 31.18 \\
\hline Self-efficacy qualitative analysis & 66.00 & 70 & 27.52 \\
\hline Age & 37.27 & 37 & 10.41 \\
\hline Gender 1 = male* & 0.42 & - & - \\
\hline Research output & 5.96 & 3.000 & 8.08 \\
\hline Preference for quantitative methods over qualitative & 0.40 & .500 & .44 \\
\hline Married* & 0.53 & - & - \\
\hline Dependent children & 1.11 & 1 & 1.27 \\
\hline
\end{tabular}

DOHET, Department of Higher Education and Training; ISI, Institute for Scientific Information; IBSS, International Bibliography of the Social Sciences.

*, Binary variable-proportion shown instead of mean.

$N=104$.

TABLE 2: Descriptive statistics: Doctoral designation.

\begin{tabular}{|c|c|c|c|}
\hline Variable & Mean/Proportion & Median & Standard deviation \\
\hline Job satisfaction & 14.32 & 15 & 4.39 \\
\hline Satisfaction with teaching & 3.92 & 4 & 1.57 \\
\hline Satisfaction with administration & 2.38 & 1 & 1.8 \\
\hline Satisfaction with research & 4.83 & 5 & 1.76 \\
\hline Self-efficacy research & 461.69 & 470 & 79.53 \\
\hline Self-efficacy DOHET publication & 80.85 & 90 & 21.93 \\
\hline Self-efficacy conference proceedings & 82.11 & 90 & 21.56 \\
\hline Self-efficacy conference presentations & 90.35 & 100 & 13.74 \\
\hline Self-efficacy statistical analysis & 48.59 & 50 & 34.36 \\
\hline Self-efficacy qualitative analysis & 75.49 & 80 & 27.13 \\
\hline Age & 40.55 & 38 & 8.89 \\
\hline Gender 1 = male* & 0.44 & - & - \\
\hline Years as a researcher & 10.39 & 9 & 6.64 \\
\hline Preference for quantitative methods over qualitative & 0.57 & 0.5 & 1.11 \\
\hline Married* & 0.58 & - & - \\
\hline Dependent children & 0.90 & 0.0 & 1.11 \\
\hline
\end{tabular}

DOHET, Department of Higher Education and Training; ISI, Institute for Scientific Information; IBSS, International Bibliography of the Social Sciences.

*, Binary variable-proportion shown instead of mean.

$N=71$.

suggest that underlying effects differentiate these cohorts and that there may be implications for the transition of individuals from one cohort to another based on these findings. Having highlighted differences between the cohorts based on descriptive findings, the reports of the inferential testing of the hypotheses will be reported and discussed in more detail.

\section{Ethical considerations}

This research, as with all other research conducted on humans, has been conducted in accordance with national and international guidelines; and approval was obtained from the University's Ethics Committee prior to the research.

\section{Potential benefits and hazards}

Potential dangers (related to physical, psychological or disclosure) were reduced by ensuring that all information was kept anonymous; and relationships in the data were only reported at the aggregated level.

\section{Recruitment procedures}

Participation was voluntary and a consent form was given to subjects to sign. A cover sheet was also given to subjects, which informed them that participation was voluntary and that they were welcome to withdraw from the study at any time. 
TABLE 3: Descriptive statistics: Professorial designation.

\begin{tabular}{|c|c|c|c|}
\hline Variable & Mean/Proportion & Median & Standard deviation \\
\hline Job satisfaction & 14.82 & 15 & 3.7 \\
\hline Satisfaction with teaching & 3.53 & 4 & 1.37 \\
\hline Satisfaction with administration & 2.35 & 2 & 1.36 \\
\hline Satisfaction with research & 5.53 & 6 & 1.31 \\
\hline Self-efficacy Research & 475.74 & 480 & 91.82 \\
\hline Self-efficacy DOHET publication & 89.59 & 100 & 16.32 \\
\hline Self-efficacy conference proceedings publication & 83.98 & 95 & 20.13 \\
\hline Self-efficacy conference presentations & 85.31 & 100 & 21.9 \\
\hline Self-efficacy statistical analysis & 55.53 & 60 & 36.83 \\
\hline Self-efficacy qualitative analysis & 76.63 & 80 & 26.60 \\
\hline Age & 48 & 48 & 9.6 \\
\hline Gender $1=$ male $*$ & 0.63 & 1 & 0.49 \\
\hline Research output & 59.06 & 35 & 57.91 \\
\hline Preference for quantitative methods over qualitative & 0.41 & 0.5 & 0.44 \\
\hline Married* & 0.65 & - & 0.48 \\
\hline Dependent children & 1.37 & 1 & 1.5 \\
\hline
\end{tabular}

DOHET, Department of Higher Education and Training; ISI, Institute for Scientific Information; IBSS, International Bibliography of the Social Sciences.

*, Binary variable-proportion shown instead of mean.

$*$, Binary
$N=49$.

\section{Informed consent}

As indicated above, subjects were given a consent form to sign and were fully appraised of their rights to withdraw their consent at any time.

\section{Data protection}

Data were archived on a password-protected computer. The computer, in turn, was protected by the University's password-protected office alarm system. The building in which the office is located is patrolled by University security. To further insure the anonymity of the subjects, no information was collected that could identify the specific individuals concerned; and results were reported as aggregated data to further ensure that individuals' data were kept anonymous.

\section{Trustworthiness}

\section{Reliability and validity}

External validity was taken to exist; the results of the study are expected to be generalisable to other higher educational institutions in the South African context to the extent that they share similarities with the one under study. The reliability of scale items was tested using tests of Cronbach's Alpha (reported above). A sampling protocol was used so as to not introduce extraneous variance into the sampling process. Piloting was also used to ensure that the procedures of the study and the use of scale items were reliable and that threats to reliability and validity were addressed. Internal validity was maintained through careful consideration of the research design, as well as the use of appropriate measures and scales; in all cases, precedent was followed to ensure scientific rigour. Alternative explanations for the results were considered. Given that statistical methods cannot ascribe causality, these results are taken to either support or contest theory that predicts certain associations. This is acknowledged as a limitation of this research, which it shares with different forms of empirical research. Another limitation of this study is that it is cross-sectional and does not offer insight into potential trends in the data over time.

\section{Results}

In the Methods section, the univariate results were reported. The bivariate and multivariate results are now reported and discussed. The hypotheses are tested against the multivariate results, as these are taken to reflect the multivariate nature of real world relationships.

\section{Hypothesis 1 (Mr/Ms designation)}

\section{Bivariate results}

According to the Spearman tests, for individuals without doctoral or professorial designations, total research output was found to be associated negatively with satisfaction with teaching $(-0.207 ; p<0.035)$.

For this cohort, research output is, however, found to be both positively and significantly associated with age $(0.316$; $p<0.001)$, years of experience as a researcher $(0.488 ; p<$ $0.0001)$, marriage $(0.235 ; p<0.016)$ and dependent children $(0.256 ; p<0.009)$. As age increases, research output is also found to increase. Similarly, as years of experience as a researcher increase, so does research productivity. Those that are married are found to have significantly higher levels of research productivity than those who are not. Individuals with more dependent children are found to have significantly higher levels of research productivity. These associations support the predictions of human capital theory (Becker 1964), in that time spent exposed to the context of research underlies these measures. Having reported and discussed the bivariate results, the results of the tests of logistic regression are now considered. 


\section{Multivariate results}

The logistic regression model was run, with the full model of variables included. According to the null model, the classification accuracy of the prediction that all cases were not part of the $\mathrm{Mr} / \mathrm{Ms}$ category was $53.6 \%$. The exponentiated intercept was not significant, according to the Wald test $(\mathrm{W}=1.141)$. The omnibus tests of model coefficients returned a Chi-square value of 135.96 for the equation $(d f=11$; $p<0.0001$ ). The pseudo $r$-squared values for the model were 0.455 for the Cox and Snell $r$-squared test and 0.608 for the Nagelkerke $r$-squared. According to the latter, about $61 \%$ of the variance in the dependent variable was contributed by the independent variables. The Hosmer and Lemeshow Chisquared value was $20.733(d f=8 ; p<0.008)$, which indicated potential problems with the specification of the model. However, given the sensitivity of this test to sample size, this was not taken to be problematic.

According to the classification table, the predictive capacity of the model improved from 53.6\% according to the first table to $84.4 \%$ in the second classification table, an increase of 57.46 in classification accuracy. The correlations between the variables were examined in order to avoid suppressor effects in the logistic regression analysis. Variables had been included based on substantive, or theoretical, criteria and singularity and multicollinearity were avoided through the inclusion of appropriate variables in the model. Table 4 reports the statistics of the predictors of the different designation items, in the form of odds ratios (exponentiated intercept value, or $\operatorname{Exp}[\beta])$. In terms of satisfaction with teaching, when the value of the satisfaction with teaching variable rises by one unit, there is a 1.43 times higher likelihood of falling into this designation category. These results, however, are unstandardised and relate to multivariate effects, or effects that take into account the influence of the other variables in the equation. Bootstrapping was applied; all significant associations reported and discussed are supported by bootstrapping results, unless otherwise indicated.

Certain features of the comparative analysis are now discussed here. To avoid redundancy, the discussion of certain relationships is not repeated in later sections.
The exponentiated coefficient comparisons across the designation groups are reported in Table 4.

On the basis of the significant associations for Hypothesis 1 , the alternative hypothesis was accepted and the null hypothesis was rejected. According to the multivariate results, individuals within the $\mathrm{Mr} / \mathrm{Ms}$ designation group are found to be significantly more satisfied in their jobs than their counterparts. This contrast is strongest with regard to those falling into the doctoral designation category. Similarly, this same contrast is evident with regard to satisfaction with teaching.

A primary differentiation between those without doctoral designation and those with doctoral designation seems to be along the lines of satisfaction with teaching as well as with job satisfaction. The significantly higher levels of job satisfaction of individuals in the $\mathrm{Mr} / \mathrm{Ms}$ category relative to the comparatively more job-dissatisfied cohort of individuals falling into the doctoral designation group seems to signal the presence of underlying effects. Further research is recommended; particularly qualitative research that can investigate the causal mechanisms underlying these effects.

For the purposes of further analysis, partial correlation analysis was used to check if the point bi-serial correlation between each of these designations and job satisfaction was still significant when satisfaction with teaching was controlled. When satisfaction with teaching was controlled, individuals in the $\mathrm{Mr} / \mathrm{Ms}$ designation group were still found to be significantly more satisfied with their jobs $(0.216 ; p<0.001)$. Similarly, their high levels of satisfaction with teaching were robust to the influence of job satisfaction $(0.364 ; p>0.0001)$. For the doctoral designation cohort, their negative association with satisfaction with teaching was also robust to the influence of job satisfaction $(-0.161 ; p<0.016)$, and their negative association with job satisfaction was robust to the influence of satisfaction with teaching $(-0.150 ; p<0.025)$.

On the basis of these results it is argued that individuals who derive their primary satisfaction from teaching may

TABLE 4: Exponentiated coefficient comparisons across designation groups.

\begin{tabular}{|c|c|c|c|}
\hline Variable & Mr/Ms designation & Doctoral designation & Professorial designation \\
\hline Job satisfaction & $1.222 * *$ & $-0.899 * *$ & 0.975 \\
\hline Satisfaction: Teaching & $1.430 *$ & $-0.787^{*}$ & -0.847 \\
\hline Satisfaction: Administration & $-0.701 *$ & 1.142 & $1.259^{\wedge}$ \\
\hline Satisfaction: Research & -0.891 & 0.889 & $\begin{array}{c}1.364 * \text { (significance not supported by } \\
\text { bootstrap confidence intervals; }-0.111 \\
\text { lower; } 0.903 \text { upper) }\end{array}$ \\
\hline Self-efficacy: Research & $-0.992 * *$ & $1.008 * *$ & 1.001 \\
\hline Years as a researcher & $-0.913^{*}$ & 1.019 & $1.086 * *$ \\
\hline Research outputs & $-0.911 * *$ & $-0.983 * *$ & $1.037 * *$ \\
\hline $\begin{array}{l}\text { Preference for quantitative methods over } \\
\text { qualitative methods }\end{array}$ & -0.865 & 1.248 & $-0.282^{*}$ \\
\hline Marriage & -0.934 & 1.281 & -0.941 \\
\hline Dependent children & 1.342 & $-0.730 *$ & 1.193 \\
\hline Constant & 4.385 & -0.414 & $0.011 *$ \\
\hline
\end{tabular}

$p<0.05$ is reported as '*'; $p<0.001$ is reported as '**' 
possibly face a constraint to career progression in this context. This supports Weber's (1919) observation, as well as more contemporary arguments that teaching and research commitments can be 'time-consuming, diverse, and conflicting' (Toews \& Yazedjian 2007:113) - the result of having to balance these as different roles that compete with each other for resources, particularly time (Brazeau \& Woodward 2012; Hattie \& Marsh 1996). Similarly, these results support findings in other contexts that time spent on teaching is associated negatively with research productivity (Barbezat 2006). Indeed, time and learning investments in teaching might not represent specific human capital (Becker 1964) which would be the case if it had no influence on productivity in research (a different context than teaching); in fact, this seems to be a case of negative general human capital, because they might be related, but negatively.

This result might have implications for retention, particularly in a context that already faces relatively high levels of academic turnover (Pienaar \& Bester 2008; Samuel \& Chipunza 2013). If research productivity is particularly sensitive to time investments (Toews \& Yazedjian 2007) then finding a balance between teaching and research (without neglecting either) might be a necessary, albeit not sufficient, condition for career progression to the other designation levels.

Another dimension of the difference between these two cohorts is the significant dissatisfaction of members of the $\mathrm{Mr} / \mathrm{Ms}$ group with administration. The ability to deal with administrative tasks is yet another dimension of role conflict in academic work (Brazeau \& Woodward 2012). Administrative skills, including attention to detail, are necessary for academic career progression along the administrative path of academic management (Leonard 1987). Members of the professorial designation are found to have both weak and positive associations with satisfaction with administration. If individuals that are relatively more dissatisfied with administration are significantly more likely to be in the $\mathrm{Mr} / \mathrm{Ms}$ designation category, then it is argued that the ability to resolve issues related to dissatisfaction with administration might be another 'crisis milestone' that may need to be resolved in order for career progression to occur.

Another significant differentiation between the $\mathrm{Mr} / \mathrm{Ms}$ (significantly lower) and doctoral (significantly higher) cohorts is clearly evident in the differences in self-efficacy related to research. It is possible that an underlying causal mechanism related to self-efficacy may underlie career progression in this context, following Bandura's (2006) predictions that endowments of self-efficacy are directly related to investments of time and effort in tasks and activities.

This progression, however, does not seem to be reflected in research outputs, as the differentiation between the three cohorts on the basis of research output seems to be at the professorial level. The results of the testing of Hypothesis 2 are now reported and discussed.

\section{Hypothesis 2 (Doctoral designation) Bivariate results}

According to bivariate Spearman tests for this cohort, total units of research output were found to be associated negatively with satisfaction with teaching $(-0.205 ; p<0.024)$. For individuals with doctoral or professorial designations, total units of research output were found to be associated both significantly and positively with all the measures of research self-efficacy except self-efficacy relating to statistical analysis $(0.111 ; p<0.225)$, age $(0.377 ; p<0.0001)$ and years of experience as a researcher $(0.613 ; p<0.0001)$. In other words, as self-reported levels of self-efficacy related to statistical analysis rise, research output is not found to rise significantly in testing for individuals that have either a doctorate or a professorial designation. However, as age and experience as a researcher increase, research productivity is found to increase for individuals in these categories.

\section{Multivariate results}

According to the null model, the classification accuracy value was $68.8 \%$; the prediction that all cases were not part of the doctoral category. The exponentiated intercept term was significant $($ Wald $=29.918 ; d f=1 ; \beta=-0.788 ; \operatorname{Exp}(\beta)=$ $0.455 ; p<0.0001)$. The omnibus tests of the model coefficients returned a value of 38.695 for the model $(d f=11 ; p<0.0001)$. The pseudo $r$-squared values (Cox and Snell $r$-square $=0.159$; Nagelkerke $r$-square $=0.223$ ) suggested that the predictors in the model accounted for just less than a quarter of the variance in the dependent variable. This is less variance predicted than in the case of the predictors of the $\mathrm{Mr} / \mathrm{Ms}$ designation. The Hosmer and Lemeshow Chi-squared value was 2.871 $(d f=8 ; p<0.942)$, suggesting that the model was relatively well specified. The predicted values in the classification reported an overall percentage value of 73.2. This reflected an increase in the predicted classification accuracy of $6.4 \%$ over the original classification accuracy value. The correlations between the variables were again considered, and potential singularity and multicollinearity were taken into account in order to avoid potential cases of suppressor effects. Table 4 reports the predictors of doctoral designation.

According to the multivariate results, individuals with a doctoral designation were found to be significantly less job satisfied, had significantly lower levels of satisfaction with teaching, had significantly higher levels of self-efficacy related to research and had significantly fewer dependent children. The latter result was unexpected, given that the influence of time was controlled through the inclusion of years as a researcher, a covariate which was strongly correlated with age (Pearson 0.654; $p<0.0001 /$ Spearman 0.620; $p<0.0001$ ).

It is possible that the negative association with dependent children (but not for marriage) for this cohort reflects the influence of some degree of work-to-family spillover (Dilworth 2004; Dilworth \& Kingsbury 2005), if doctoral attainment can be considered a dimension of 'work'. Although no gender effect was associated significantly with this cohort designation, it is possible that having a family 
might constrain progression to the doctoral designation category and that this effect is present for both men and women.

Further research is suggested with regard to this relationship, because this potential work-to-family spillover effect might have other implications for an individual's welfare if there are social costs associated with doctoral degree attainment. The results of the testing of Hypothesis 3 are now reported and discussed.

\section{Hypothesis 3 (Professorial designation)}

\section{Bivariate results}

For individuals with professorial designations, total research output is associated significantly with all the research selfefficacy items except for statistical analysis $(p<0.06)$.

For this cohort, total research productivity is associated both positively and significantly with age $(0.307 ; p<0.032)$, male gender (Spearman point-biserial correlation $=0.416 ; p<$ $0.003)$, years of experience as a researcher $(0.671 ; p<0.0001)$, doctoral supervision $(0.345 ; p<0.015)$, a preference for quantitative methods over qualitative methods $(0.505 ; p<$ $0.0001)$ and marriage $(0.317 ; p<0.026)$. For individuals with professorial designations, as age and years of experience as a researcher increase, total research productivity is also found to increase. Men are found to be significantly more research productive than women. Individuals who have supervised more doctoral students and who have a preference for quantitative methods over qualitative are found to have significantly higher levels of total research productivity. Those who are married are also found to have higher levels of total research productivity than those who are not married.

\section{Multivariate results}

According to the null model, the classification accuracy of the prediction that not all cases were part of the professorial category was $78.1 \%$. The exponentiated intercept value was significant $(\beta=-1.273 ; \operatorname{Exp}(\beta)=0.280 ; d f=1 ;$ Wald $=62.033$; $p<0.001)$. The omnibus tests of the model coefficients were significant, with a Chi-squared value of $92.263(d f=11$; $p<0.0001)$ for the model. The pseudo $r$-squared values for the model were 0.338 for the Cox and Snell $r$-square statistic and 0.519 for the Nagelkerke $r$-square statistic. Just over half of the variance in the dependent variable was taken to be explained by the predictor variables in the model. The Hosmer and Lemeshow test statistic was not significant (Chi-square $=2.256 ; \mathrm{df}=8 ; p<0.972)$. This was taken to suggest few problems with the specification of the model. Once again, correlations between the variables, potential singularity and multicollinearity were taken into account in order to avoid the influence of suppressor effects on the interpretation of the results. According to the predicted values in the classification table $(88.4 \%)$, the predictive capacity of the model reflects an improvement on the nonpredictor classification table of $13.2 \%$.
Whereas job satisfaction, satisfaction with teaching and satisfaction with administration are all associated significantly with either or both of the other two tested cohorts, none of these are significant for the professorial cohort. It is argued that it is plausible that development to this level follows a path that requires the resolution, or 'negotiation' of certain issues. In the absence of causal research, this remains an argument that cannot be causally verified, but these results are taken to offer some support for this argument; that some degree of integration or balance between the teaching and research roles may have been achieved (Burke \& Rau 2010).

Interestingly, members of this cohort overall are found to have a significant preference for qualitative methods over quantitative methods, notwithstanding the relatively higher research productivity of those with a preference for quantitative methods. However, given that there are disciplinary differences between fields (Mbali 2010; Su 2014), which may also be related to geographical differences in preferences for quantitative versus qualitative methods (Röbken 2009), it is also possible that these findings reflect disciplinary differences. Having reported and discussed the findings of this research, conclusions are now presented and recommendations are made.

\section{Discussion Outline of the results}

The aim of this research was to test theory that predicted differences between academics that relate to career progression for the three cohorts in this context. The central argument made in this study was that there are certain issues, or crisis milestones, that typically need to be resolved in order for career progression to doctoral and professorial designations to occur. It was also argued that to negotiate, or progress 'past' these crisis milestones, an academic may have to find a balance between different and often conflicting demands, or roles, at different career stages.

Given the limitations of cross-sectional associative research designs and the limitations of statistical methods, this study was not able to ascribe causal relationships. Nevertheless, on the basis of these findings, it is argued that these results may support the central thesis of this research, and theory derived from the literature that predicts these relationships. Further research is recommended, particularly qualitative methods that can explore the causal mechanisms that underlie these findings.

These findings suggest that three dominant career crisis milestones stand out. It was concluded that three primary role conflicts may possibly represent crisis milestones in an academic career in this context.

\section{Dominant career crisis milestones}

\section{Tension between teaching and research}

Firstly, across the entire sample, individuals that were relatively more satisfied with teaching are found to have 
significantly lower levels of research output. This reflected the tension between teaching and research, which exists across different contexts (Barbezat 2006; Brazeau \& Woodward 2012; Burke \& Rau 2010; Fox 1992; Hattie \& Marsh 1996; Toews \& Yazedjian 2007). Whereas individuals in the $\mathrm{Mr} / \mathrm{Ms}$ cohort were found to be significantly more satisfied with teaching, individuals that are part of the doctoral cohort were found to be significantly less satisfied with teaching. It was concluded that this potential role conflict may need to be resolved to attain doctoral or professorial designations; a balance between these two roles and their demands for time and other resources might need to be attained.

\section{Self-efficacy}

Secondly, it is concluded that another dominant crisis milestone may relate to research self-efficacy (Bandura 2006), which is associated negatively with the $\mathrm{Mr} / \mathrm{Ms}$ cohort yet is associated positively with the doctoral cohort. Career progression between these two stages might be a function of endowments of self-efficacy, which might, in turn, be a function of role conflicts if these constrain time spent in research (Barbezat 2006). This is predicted to be associated with the development of research self-efficacy, through learning by doing (Bandura 2006).

\section{Family responsibilities}

Thirdly, it is concluded that another crisis milestone may exist in the form of family responsibilities associated with dependent children and potential family-to-work spillovers (Dilworth 2004; Dilworth \& Kingsbury 2005); individuals in the doctoral cohort are found to have significantly fewer dependent children. This effect was found to be present for both male and female academics. The need to balance the family life role with work career role needs might be an important dimension of progression to doctoral attainment.

\section{Practical implications and recommendations}

These findings suggest that career progression between the three cohort levels investigated in this research is dominated by the need to balance different types of role conflict and to develop self-efficacy related to research.

Academics should strive for balance between the roles of research, teaching and service; this might require 'fencing off' time (Toews \& Yazedjian 2007). Academics should perhaps be counselled and assisted to balance these roles (and the time requirements associated with each).

Staff should strive to know the requisite 'mix' of, or balance of, different requirements for tenure and promotion, both explicit and implicit (Toews \& Yazedjian 2007), so as not to neglect any of them. Knowledge of the specific crisis milestones faced in this context can provide the basis for formal programmes to address these potential challenges directly. Formal research mentorship programmes (Nundulall \& Reddy 2011), professional development associations (Berger 2014), educational development programmes (Cilliers \&
Herman 2010), short courses as well as in-depth, intensive staff development programmes (Ginns, Kitay \& Prosser 2010) can help with this.

\section{Conclusion}

The objective of this research was to test differences in academic designations as a proxy for career advancement of academics. More specifically, this research sought to identify potential 'crisis milestones', or constraints to career progression. A research design was implemented, using logistic regression analysis.

It is concluded that theory that predicts the presence of these crisis milestones in this context is supported and it is acknowledged that further research is needed in order to establish the causal mechanisms that underlie these findings. However, it is argued that these findings will generalise to other university contexts, particularly in South Africa. It is suggested that the recommendations provided in this article be considered for future research.

It is perhaps the responsibility of university management to seek to reduce the human cost associated with these role conflicts and other issues that constrain academic career progression; particularly those that may exist simply because of imbalances between roles experienced in this context.

\section{Acknowledgements}

All those that participated in the study are hereby acknowledged and thanked for their contribution to this research. The helpful comments of the reviewers are also acknowledged and their role in improving the manuscript is also recognised here.

\section{Competing interests}

The author declares that he has no financial or personal relationship(s) that may have inappropriately influenced him in writing this article.

\section{References}

Arvey, R.D., Bouchard, T.J., Segal, N.L. \& Abraham, L.M., 1989, 'Job satisfaction: Environmental and genetic components', Journal of Applied Psychology 74(2), 187-192. http://dx.doi.org/10.1037/0021-9010.74.2.187

Bandura, A., 2006, 'Guide for constructing self-efficacy scales', in F. Pajares \& T. Urdan (eds.), Self-efficacy beliefs of adolescents, vol. 5, pp. 307-337, Information Age Publishing, Greenwich, CT.

Barbezat, D.A., 2006, 'Gender differences in research patterns among PhD economists' Journal of Economic Education 37(3), 359-375. http://dx.doi.org/10.3200/ JECE.37.3.359-375

Becker, G.S., 1964, Human capital, University of Chicago Press, Chicago, IL.

Berger, J.I. 2014, 'Role of professional development associations in the future of our field', Adult Learning 25(1), 31-33. http://dx.doi.org/10.1177/1045159513510149

Brazeau, G.A. \& Woodward, M.B., 2012, 'Rethinking faculty career development strategies', American Journal of Pharmaceutical Education 76(6), Article 101, 1-2.

Brown-Wilson, D. \& Parry, E., 2013, 'Career progression in older managers', Employee Relations 35(3), 309-321. http://dx.doi.org/10.1108/01425451311320495

Burke, L.A. \&, Rau, B., 2010, 'The research-teaching gap in management', Academy of Management Learning \& Education 9(1), 132-143. http://dx.doi.org/10.5465/ AMLE.2010.48661196

Cilliers, F.J. \& Herman, N., 2010, 'Impact of an educational development programme on teaching practice of academics at a research-intensive university', International
Journal for Academic Development 15(3), 253-267. http://dx.doi.org/10.1080/13 Journal for Academic
$60144 X .2010 .497698$ 
Cresswell, J.W., 2003, Research design. Qualitative, quantitative, and mixed methods approaches, 2nd edn., Sage Publications, Inc., Thousand Oaks, CA.

Deacon, R., Osman, R. \& Buchler, M., 2010, 'Scholarship in teacher education in South Africa, 1995-2006', Perspectives in Education 28(3), 1-12.

Dilworth, J.E.L., 2004, 'Predictors of negative spillover from family to work', Journa of Family Issues 25(2), 241-261. http://dx.doi.org/10.1177/0192513X03257406

Dilworth, J.E.L. \& Kingsbury, N., 2005, 'Home-to-job spillover for Generation X, Boomers, and Matures: A comparison', Journal of Family and Economic Issues 26(2), 267-281. http://dx.doi.org/10.1007/s10834-005-3525-9

Driver, M.J., 1994, 'Careers: A review of personal and organizational research', in C.L. Cooper \& I.T. Robertson (eds.), Key reviews in managerial psychology: Concepts and research for practice, pp. 237-269, John Wiley \& Sons, Chichester.

Fox, M.F., 1992, 'Research, teaching, and publication productivity: Mutuality versus competition in academia', Sociology of Education 65(4), 293-305. http://dx.doi. org/10.2307/2112772

Ginns, P., Kitay, J. \& Prosser, M., 2010, 'Transfer of academic staff learning in a researchintensive university', Teaching in Higher Education 15(3), 235-246. http://dx.doi. org $/ 10.1080 / 13562511003740783$

Hattie, J. \& Marsh, H.W., 1996, 'The relationship between research and teaching: A meta-analysis', Review of Educational Research 66(4), 507-542. http://dx.doi. org/10.3102/00346543066004507

Lam, A., 2007, 'Knowledge networks and careers: Academic scientists in IndustryUniversity links', Journal of Management Studies 44(6), 993-1016. http://dx.doi. org/10.1111/j.1467-6486.2007.00696.x

Lautenbach, G., 2010, 'Expansive learning cycles: Lecturers using educational technologies for teaching and learning', South African Journal of Higher Education 24(5), 699-715

Leonard, W.P., 1987, 'An alternative career path to academic administration', Journal of Academic Librarianship 13(2), 44-45.

Mbali, C., 2010, 'Against journal articles for measuring value in university output', South African Journal of Higher Education 24(5), 745-757.

Muchinsky, P.M., 1983, Psychology applied to work: An introduction to industrial and organizational psychology, Dorsey Press, Homewood, PA

Nundulall, R. \& Reddy, K., 2011, 'Mentorship as a strategy to improve research output at tertiary institutions: A case study of University of Johannesburg', South African Journal of Higher Education 25(6), 1155-1177.
O'Brien, K.R. \& Hapgood, K.P., 2012, 'The academic jungle: Ecosystem modelling reveals why women are driven out of research', Oikos 121(7), 999-1004. http://dx.doi.org/10.1111/j.1600-0706.2012.20601.x

O'Mahony, S. \& Bechky, B.A., 2006, 'Stretchwork: Managing the career progression paradox in external labor markets', Academy of Management Journal 49(5), 918941. http://dx.doi.org/10.5465/AMJ.2006.22798174

Pienaar, C. \& Bester, C., 2008, 'The retention of academics in the early career phase', SA Journal of Human Resource Management 6(2), 32-41.

Rabe, M. \& Rugunanan, P., 2011, 'Is there life after Sociology? Exploring the career paths of former South African academics in Sociology', South African Review of Sociology 42(3), 60-78. http://dx.doi.org/10.1080/21528586.2011.621239

Röbken, H., 2009, 'Career paths of German Business Administration academics', Zeitschrift für Personalforschung 23(3), 219-236.

Robyn, A. \& du Preez, R., 2013, 'Intention to quit amongst Generation Y academics in higher education', South African Journal of Industrial Psychology 39(1), 1-14.

Samuel, M.O. \& Chipunza, C., 2013, 'Attrition and retention of senior academics at institutions of higher learning in South Africa: the strategies, complexities and realities', Journal of Social Sciences 35(2), 97-109.

Srour, I., Abdul-Malak, M-A., Itani, M., Bakshan, A. \& Sidani, Y., 2013, 'Career planning and progression for Engineering Management graduates: An exploratory study', Engineering Management Journal 25(3), 85-100.

Su, X., 2014, 'Rank advancement in academia: What are the roles of postdoctoral training?', The Journal of Higher Education 85(1), 65-90. http://dx.doi. org/10.1353/jhe.2014.0002

Toews, M.L. \& Yazedjian, A, 2007, 'The three-ring circus of academia: How to become the ringmaster', Innovative Higher Education 32, 113-122. http://dx.doi. org/10.1007/s10755-007-9046-8

Walsh, J., 2012, 'Not worth the sacrifice? Women's aspirations and career progression in law firms', Gender, Work \& Organization 19(5), 508-531. http://dx.doi. org/10.1111/j.1468-0432.2012.00607.x

Weber, M., 1919, 'Science as a vocation [Wissenschaft als beruf]', in Tubingen, Gesammlte Aufsaetze zur Wissenschaftslehre, pp. 524-555, Duncker \& Humboldt, Munich.

World Economic Forum, 2012, The Global Competitiveness Report 2012-2013, viewed 28 January 2014, from http://www3.weforum.org/docs/WEF_ GlobalCompetitivenessReport_2012-13.pdf 